\title{
Las ideas en el pensamiento de política exterior de Venezuela bajo la revolución bolivariana. Continuidades y rupturas: 1990-2016*
}

\section{The ideas in the foreign policy thinking of Venezuela under the Bolivarian revolution. Continuities and ruptures: 1990-2016}

\author{
Raúl Bernal-Meza**
}

\section{Resumen}

El artículo analiza las ideas en la formulación de la política exterior venezolana, haciendo, previamente, una reflexión teórica sobre el papel de la ideas en las políticas exteriores en general. Fuentes y metodología se basan en los estudios de autores que han analizado la política exterior del período. Sobre esos textos hacemos análisis para extraer las ideas y pensamientos que justificaron o sustentaron la política. Siendo Venezuela, una "potencia regional secundaria influyente en la política regional e internacional, el texto aporta a la discusión del pensamiento internacional actual.

Palabras clave: Venezuela, pensamiento internacional, política exterior, regionalismo, América Latina.

\begin{abstract}
Introducing a theoretical reflection on the role of ideas in the formulation of foreign policy, they are analyzed in Venezuela. Sources and methodology are based on studies of authors who have analyzed the foreign policy of the period. On those texts do analysis to extract the ideas and thoughts that justified or sustained politics. Venezuela being a "regional secondary power" influential in regional and international politics, the text brings to the discussion of current international thinking.
\end{abstract}

Keywords: Venezuela, international affairs, foreign policy, international thinking, regionalism, Latin America.

Recibido: 11 noviembre 2016

Aceptado: 7 enero 2017

\footnotetext{
${ }^{*}$ Investigación desarrollada en el marco del Proyecto Fondecyt $\mathrm{N}^{\circ} 1130380$ y en el Instituto de Estudios Internacionales, INTE, de la Universidad Arturo Prat (Chile). El autor agradece los comentarios a la versión preliminar del Dr. Peter Birle, Director Académico del Instituto Latinoamericano de Berlín.

Chileno. Doctor en Sociología, con especialidad en Relaciones Internacionales (Université de la SorbonnePontificia Universidad Católica Argentina Santa María de los Buenos Aires). Investigador del INTE de Universidad Arturo Prat. Profesor Titular de Relaciones Internacionales de la Universidad Nacional del Centro de la Provincia de Buenos Aires y Profesor de las Universidades de Buenos Aires y Nacional de La Plata. bernalmeza@hotmail.com
}

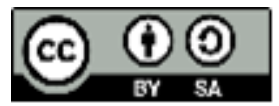




\section{Introducción}

La política exterior es entendida, principalmente, como una política pública de los Estados, dirigidas al ámbito internacional, con el fin de promover o modificar condiciones que hagan posible la seguridad y el bienestar económico y, en el caso de países como los nuestros, facilitar las políticas de desarrollo. En la opinión de Luciano Tomassini ${ }^{1}$, Roberto Russell $^{2}$, Raúl Bernal-Meza ${ }^{3}$ y Amado Cervo ${ }^{4}$, la política exterior se nutre con elementos valorativos, históricos, intereses e imágenes que reflejan las ideas que sobre el mundo y sí mismos tienen sus formuladores y tomadores de decisión y expresan lo que aspiran a hacer en él. Identificar cuáles son las ideas, percepciones e imágenes que se expresan en el discurso y/o la formulación de la política exterior o se proyectan a través de ésta, permite entender por qué los países hacen lo que hacen en política exterior.

Sin embargo, la ideología de los gobernantes, las visiones -incluso a veces radicales- sobre el orden internacional, y la configuración o participación en alianzas o "ejes" quedaban a menudo subordinadas a las lógicas del sistema político y de las necesidades de la propia política económica nacional y el modelo de inserción internacional, como bien ejemplificó José Paradiso ${ }^{5}$ al historiar y analizar la política exterior argentina. Autores como Heraldo Muñoz ${ }^{6}$, Raúl Bernal-Meza ${ }^{7}$, Amado Cervo ${ }^{8}$, Rafael Velázquez ${ }^{9}$, Alejandro Simonoff ${ }^{10}$ y Eduardo Velosa ${ }^{11}$, han puesto de relevancia la

\footnotetext{
${ }^{1}$ Luciano Tomassini, "Elementos para el análisis de la política exterior", Estudios Internacionales, Vol. 20, $\mathrm{N}^{\circ} 78$ (1987): 125-157.

${ }^{2}$ Roberto Russel, Política exterior y toma de decisiones en América Latina, Buenos Aires: RIAL y Grupo Editor Latinoamericano, 1990. También su "Introducción", en R. Russell (editor), Enfoques teóricos y metodológicos para el estudio de la política exterior, Buenos Aires, RIAL y Grupo Editor Latinoamericano, 1992, p.: 7-18.

${ }^{3}$ Raúl Bernal-Meza, América Latina en el Mundo. El pensamiento latinoamericano y la teoría de relaciones internacionales, Buenos Aires, Nuevohacer/Grupo Editor Latinoamericano, [2005], 2013.

${ }_{5}^{4}$ Amado Cervo, Inserção Internacional. Formação dos conceitos brasileiros, São Paulo, Editora Saraiva, 2008.

5 José Paradiso, Debates y trayectoria de la politica exterior argentina, Buenos Aires, Grupo Editor Latinoamericano, 1993; también en "Ideas, ideologías y política exterior en Argentina", en Revista DEP, Diplomacia, Estrategia y Política, Brasília, 2007, p. 5: 5-25.

${ }^{6}$ Heraldo Muñoz, Las relaciones exteriores del gobierno militar chileno, Santiago, Ediciones del Ornitorrinco, 1986.

${ }^{7}$ Raúl Bernal-Meza, "Teorías, ideas políticas y percepciones en la formulación de la política exterior chilena: 1945-1987”, en Juan Carlos Puig (coord.), Teorías de Relaciones Internacionales y de Derecho Internacional en América Latina, Caracas, Universidad Simón Bolívar/Organización de los Estados Americanos, 1989, p. 149-270; y Bernal-Meza, op. cit.

8 Amado Cervo, Relações Internacionais da América Latina. Velhos e novos paradigmas, Brasilia, FUNAG/Instituto Brasileiro de Relações Internacionais, 2001, y en Cervo, 2008, op.cit.

${ }^{9}$ Rafael Velázquez F., Factores, bases y fundamentos de la política exterior de México, México D.F., Plaza y Valdés S.A., 2007, Segunda edición.

${ }^{10}$ Alejandro Simonoff, Teorías en movimiento. Los orígenes disciplinares de la política exterior y sus interpretaciones históricas, Rosario, Prohistoria, 2012.

${ }^{11}$ Eduardo Velosa P., "Las ideas y la política exterior colombiana: una mirada desde la teoría del rol nacional y el institucionalismo discursivo”, en Stefan Jost (ed.), Colombia: ¿una potencia en desarrollo? Escenarios y desafíos para su política exterior, Bogotá, Konrad Adenauer Stiftung, 2013, Segunda Edición, p. 39-53.
} 
importancia que las ideas tienen en la formulación de la política exterior de los países latinoamericanos. Judith Goldstein y Robert Keohane ${ }^{12}$ describieron en general cómo las ideas, que se definen como "creencias de individuos", pueden considerarse variables que explican los resultados políticos.

El objetivo de este trabajo es identificar las ideas que han sostenido la política exterior en Venezuela, en el período 1990-2016.

La metodología se basa en el análisis y descripción que han volcado en sus investigaciones los académicos, internacionalistas y diplomáticos venezolanos, sobre su propio país, o de autores de otros países que han realizado estudios sobre éste.

En el trabajo se sostienen dos argumentaciones. La primera, que al analizar las ideas en el pensamiento en política exterior -es decir, las macro visiones, paradigmas y concepciones de sí y del mundo- que han fundamentado las relaciones internacionales de Venezuela, ese pensamiento se ha caracterizado por dos rasgos principales: 1) la variable continuidad-ruptura, en dos ciclos (1990-1998 y 1998-2016, respectivamente) y, 2) un pensamiento internacional que Chávez construyó basado en ideas latinoamericanas de los años sesenta (estructuralismo-dependentismo), que él insertó en una base ideológica sostenida en sus propias interpretaciones de las ideas de Simón Bolívar, aggiornadas al fin del siglo XX, bajo el orden emergente de la postguerra fría y en la lectura que hizo de este nuevo escenario global.

Maduro mantuvo estas macro-visiones, y le agregó la visión internacional de un autor argentino reciente, que reforzó la visión estructuralista de las relaciones internacionales, al tiempo que le permitió marcar una diferencia supuestamente superadora, con su mentor Chávez. Sin embargo, el cambio de los contextos políticos y económicos internacional, regional y doméstico- lo llevaron a una radicalización de las ideas, que naturalmente lo alejan de la visión internacional cubana actual que Chávez constituyó en el eje de lo que debía ser una política internacional de gran activismo y exposición.

La segunda argumentación señala que, como consecuencia de la predominancia de estas líneas de pensamiento, las políticas exteriores de ambas presidencias (Chávez y Maduro) han sido más constantes o permanentes, pero con importantes rupturas con el pasado; a diferencia del antecesor presidencial de Chávez, Rafael Caldera, quien produjo cambios dentro de la continuidad de las grandes líneas históricas de la política exterior venezolana.

Este hecho dio por resultado mayores divergencias y también coincidencias, con otros países de la región, respecto de las relaciones con Estados Unidos, la integración y el regionalismo, puesto que estos dos ejes -Estados Unidos e integración/regionalismoaparecieron como temas de referencia, al señalarse en la política exterior objetivos como "autonomía" y "desarrollo". Sin embargo, los cambios políticos ocurridos en el escenario regional (Cuba y sus relaciones con Estados Unidos, cambios de gobierno en Brasil, Argentina y Uruguay) y la crisis interna, modificaron un contexto que Maduro no ha logrado articulado con un nuevo patrón de ideas. La crisis de los precios del petróleo afectó

\footnotetext{
${ }^{12}$ Judith Goldstein y Robert Keohane, "Ideas and foreign policy; an analytical framework" in J. Goldstein and R. Keohane (ed.) Ideas \& foreign policy. Beliefs, institutions and political change, Ithaca, New York, Cornell University Press, 2003, p. 3-30.
} 
el gran proyecto integracionista de ALBA y sus instrumentos energéticos (PetroAmérica, Petrocaribe y Petrosur) que fueron centrales en la estrategia regional de Chávez, sin que haya habido una actualización de las ideas o una re-evaluación de los escenarios internacionales para salir del clásico discurso antiimperialista.

\section{Ideas y pensamiento en la formulación de la política exterior}

Vale la pena recordar que Heraldo Muñoz ${ }^{13}$, en su investigación sobre las diversas perspectivas teóricas aplicadas al estudio del comportamiento externo de los países latinoamericanos, encontró que en la literatura aparecían, recurrentemente, tres temas: autonomía -como aspiración y búsqueda de su maximización-, desarrollo -como objetivo económico- y relaciones con Estados Unidos -por la importancia e influencia que la potencia tenía sobre la región-. Estos tres temas, serían claves en la formulación de la agenda temática de las presidencias de Chávez.

La importancia regional y global de Estados Unidos había retornado con mucha fuerza luego del fin de la guerra fría. Si bien algunos autores consideraron que los gobiernos latinoamericanos sobrevaloraron el papel que pasaría a jugar la potencia mundial en el nuevo orden internacional -como señalan Amado Cervo ${ }^{14}$, Cristina Pecequilo ${ }^{15}$ y Aloizio Mercadante ${ }^{16}$, para el caso de Brasil; Luis Maira ${ }^{17}$, para el caso chileno y Felipe De la $\mathrm{Balze}^{18}$, en el caso argentino- no es menos cierto que el surgimiento de Estados Unidos como líder indiscutido de la coalición vencedora de la Guerra Fría había obligado a todos los países de América Latina, con la excepción de Cuba, a replantear su política exterior y a buscar nuevas formas de entendimiento con Washington ${ }^{19}$. Como señaló Joaquín Fermandois al analizar el caso chileno (2012, p. p 477), "la existencia de una idea análoga con EE.UU. acerca del orden mundial es, a partir de los años noventa, la garantía más segura de la continuidad de las buenas relaciones que sobrevivirían en una década más turbulenta para la región, la del 2000, y hasta hoy".

\footnotetext{
${ }^{13}$ Heraldo Muñoz, "El estudio de las políticas exteriores latinoamericanas: temas y enfoques dominantes", en Manfred Wilhelmy (ed.), La formación de la política exterior: los países desarrollados y América Latina, Buenos Aires, RIAL/Grupo Editor Latinoamericano, 1987.

14 Amado Cervo, "Relaçôes Internacionais do Brasil: a era Cardoso", en Revista Brasileira de Política Internacional, 45:1 (2001): 5-35 y en Relações Internacionais da América Latina. Velhos e novos paradigmas.

${ }^{15}$ Cristina Pecequilo, "Brasil e Estados Unidos: Um enfoque contemporáneo das relações bilaterais (19902011)", en Antônio Carlos Lessa e Henrique Altemani de Oliveira (org.), Parcerias Estratégicas do Brasil: os significados e as experiências tradicionais, Belo Horizonte, Fino Traço Editora, 2013, Volume I, p. 69-90.

${ }^{16}$ Aloizio Mercadante, Brasil: de Lula a Dilma (2003-2013, Madrid, Clave intelectual, 2013.

${ }^{17}$ Luis Maira, "La Política Exterior de los Gobiernos de la Concertación. Contexto, raíces, formulación, logros y restricciones”, en Yesko Quiroga y Jaime Ensignia (ed.), Chile en la Concertación (1990-2010), Santiago, Friedrich Ebert Stiftung, 2010; Tomo II, p. 63-101.

${ }^{18}$ Felipe De la Balze, "La política exterior en tres tiempos. Los fundamentos de la nueva política exterior", en Felipe De La Balze y Eduardo Roca (ed.), Argentina y Estados Unidos. Fundamentos de una nueva alianza, Buenos Aires, CARI-ABRA, 1997, p. 11-129.

${ }^{19}$ Roberto Russell, "La Argentina del segundo centenario: ficciones y realidades de la política exterior", en Roberto Russell (ed.), Argentina 1910-2010. Balance de siglo, Buenos Aires, Ed. Taurus, 2010, p. $227-307$.
} 
Chávez reaccionaría en contra de esta tendencia y pondría a Estados Unidos como el enemigo a combatir por su política exterior, a través de modelos alternativos de integración, como ALBA, y construyendo alianzas internacionales contra-hegemónicas. Tal política internacional de confrontación con Washington no tenía antecedentes en la historia de las relaciones internacionales de Venezuela desde principios del siglo XX.

Adecuándose a los nuevos tiempos, con pragmatismo y realismo, el gobierno de Raúl Castro modificó sustancialmente sus relaciones con Estados Unidos y éste fue un acontecimiento frente al cual Maduro pareciera haberse quedado sin respuestas.

El período elegido en este estudio corresponde al más reciente. El punto de partida son los años iniciales de la década de 1990, cuando el sistema político, nacido en los acuerdos de "Punto Fijo" (1958), se derrumba, como consecuencia del intento de golpe de Estado de 1992 y la destitución, al año siguiente, del presidente Carlos Andrés Pérez.

El objetivo de la investigación aspira a hacer una contribución a la identificación de ideas, visiones y paradigmas que permitan elaborar análisis prospectivos sobre las relaciones internacionales de la región, considerando que Venezuela es reconocida como una "potencia media"20 de América Latina, con capacidades de influencia sobre las relaciones internacionales de la región y sobre las agendas temáticas de los acuerdos de regionalismo y cooperación, latinoamericanos (CELAC), pero en particular sudamericanos (UNASUR). Asimismo, la investigación aporta una lectura histórica del tiempo presente, al abordar las ideas y el pensamiento de política exterior contemporáneo de Venezuela.

\section{Los antecedentes}

Desde 1959, hasta la llegada al gobierno de Hugo Chávez, hubo elementos de continuidad en la visión sobre la política exterior. Surgieron como parte de los criterios coincidentes del Acuerdo o Pacto de Punto Fijo, que permitieron sostener el nuevo Sistema Político Venezolano, luego de la dictadura de Pérez Jiménez, que dio un fuerte carácter presidencialista al sistema político. Este rasgo se proyectará a la política exterior, fortaleciendo aún más el papel del Ejecutivo.

A partir de 1959, una política democrática; la promoción regional e internacional de la democracia representativa, conocida como "doctrina Betancourt"; una política petrolera, (donde este energético constituiría la fuente crucial de rentas para el Estado, y proveería los recursos financieros para una activa política exterior), sustentaría -vía cooperación y en forma financiera- una política tercermundista; con fuerte énfasis en la identidad de Venezuela con los países en vías de desarrollo, en especial con los países latinoamericanos y del Caribe y, coyunturalmente, con la cooperación Sur-Sur en general. A la vez, sería una política "occidentalista", que en el marco de la Guerra Fría (presencia de focos guerrilleros internos, apoyados por Cuba) y de los vínculos comerciales con Estados Unidos implicó un alineamiento no automático con las agendas políticas internacionales de Washington. Esta

\footnotetext{
${ }^{20}$ Según han Martha Ardila, "La transición internacional colombiana y la búsqueda de un nuevo rol frente a potencias regionales en Latinoamérica", en Stefan Jost (ed), op. cit. p. 643-657; y Daniel Flemes, "La política exterior colombiana desde la perspectiva del realismo clásico”, en Stefan Jost (ed), op. cit. p. 19-37.
} 
política presentó en casos un grado de autonomía relativa, pero no puso en cuestión hasta la elección de Chávez, el alineamiento de Venezuela con el bloque occidental, particularmente en el marco sub-regional y hemisférico, según afirman Andrés Serbin (2010), Edmundo González Urrutia (2008), Carlos Romero (2001) y Eva Josko de Guerón $^{21}$.

Aun cuando se pueden advertir continuidades a pesar de las rupturas, por un extenso período temporal cuyo inicio está en la recuperación del sistema democrático y la presidencia constitucional de Rómulo Betancourt (1959) y que se proyecta hasta la crisis de los años recientes, bajo el gobierno de Maduro, la continuidad estuvo en la utilización del petróleo como recurso e instrumento fundamental para una activa política exterior, caracterizada por las iniciativas de cooperación e integración Sur-Sur. Desde entonces, tres rasgos caracterizaron la formulación de la política exterior: 1) el excepcionalismo regional de Venezuela; 2) el rol decisivo del Poder Ejecutivo y 3) un marcado activismo internacional. Con distintos matices, estos tres rasgos caracterizarían también al gobierno de Chávez (Aranda, 2013; Briceño Ruiz, 2011; Corrales, 2009; González Urrutia, 2008 y 2006; Pérez, 2004).

La relación entre política exterior, activa diplomacia y petróleo estuvo históricamente asociada y la economía venezolana atada a sus precios. Según Romero y Mijares (2016),

"Venezuelan foreign policy has been characterised by a growing dependency on oil market cycles. Although not a sufficient condition, a favourable oil scenario, with high prices and/or greater State capacity to capture income is a necessary condition for formulating ambitious objectives in Venezuelan foreign policy. The interaction between this former feature and other domestic conditions, such as presidential charisma and legislative control by the governing party, have generated an important Venezuelan international activism. Three Venezuelan presidents have been known to project expansive doctrines of regional influence: the social democrats Rómulo Betancourt (1959-1964) and Carlos Andrés Pérez (1974-1979; 1989-1993), and the socialist Hugo Chávez (1999-2013). In contrast, and for reasons associated with the aforementioned conditions, each one of their successors (Raúl Leoni 1964-1969; Rafael Caldera 1969-1974 and 1994-1999, Luis Herrera Campins 1979-1984 and Nicolás Maduro 2013- ) has limited the scope of national objectives in international politics". Apoyándose en Alarcón Deza $^{22}$, señalan que "these shifts from a high intensity in foreign policy to periods of low intensity have exposed the changing conditions between each cycle. The continuity from Chávez to Maduro seems natural, since both leaders belong to the same party - the Partido Socialista Unido de Venezuela (PSUV) - the successor was anointed by the predecessor, and

\footnotetext{
${ }^{21}$ Eva Josko de Guerón, "La política exterior: continuidad y cambio, contradicción y coherencia”, en Moisés Naim y Ramón Piñango (dirs.), El caso Venezuela: una ilusión de armonía, Caracas, IESA, 1986.

${ }_{22}^{2}$ Benigno Alarcón Deza, (ed), El desafío venezolano: continuidad revolucionaria o transición democrática. Caracas, UCAB, 2014.
}

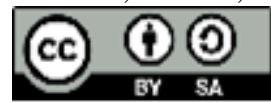


Maduro was, additionally, the longest-serving minister of foreign relations under Chávez".

La principal herencia eidética del período anterior a Chávez, con un pensamiento propio en relaciones internacionales, fue la "Doctrina Betancourt" (1959), que promovió la defensa de los sistemas democráticos de gobierno y la confrontación con los regímenes dictatoriales, en América Latina y Caribe. Venezuela se distinguió por la combinación de un sistema democrático estable a lo largo de más de tres décadas, y la explotación de sus recursos petroleros como sostén de una economía rentista que permitió una proyección internacional frecuentemente sobredimensionada; una visión que Carlos Andrés Pérez profundizó, proyectándola a países del entonces Segundo Mundo.

De allí que una referencia especial, en este período previo, merece el primer gobierno de Carlos Andrés Pérez. En primer lugar porque él extiende el sentido de la Doctrina Betancourt -originalmente restringida a los regímenes con democracia representativa (que equivalía a relaciones con los países democráticos occidentales)- a las relaciones con los países del mundo socialista (Gamus, 1989), lo que constituye un antecedente en la proyección de pluralismo internacional de la política exterior de Venezuela; en segundo lugar, porque extendió, geográficamente, la proyección y el activismo de la política exterior sostenida en la renta petrolera.

La política exterior de Carlos Andrés Pérez continuó e intensificó los lineamentos adelantados por su predecesor, adecuados a las nuevas condiciones regionales e internacionales. Como señala Gamus, "la consolidación de la crisis energética y el aumento de los precios del petróleo que se habían iniciado en los anos inmediatamente anteriores va creciendo, lo cual le otorga al gobierno venezolano mejores posibilidades de negociación con los países industrializados y mejores oportunidades para enfrentarse a la problemática Norte-Sur”.

Sin embargo, el efecto combinado de la baja de los precios internacionales del petróleo y el endeudamiento externo provocaron una crisis económica sin precedentes, con secuelas sociales y políticas que pusieron en cuestionamiento la estabilidad del sistema democrático (Serbin, 1993, p. 643).

Esta situación ayuda a explicar que los cambios que Chávez introducirá en política exterior no podrían desligarse de los cambios políticos, sociales y económicos internos del período, a pesar del hecho que las ideas sobre activismo internacional ya se habían instalado. Como señalan Miriam Saraiva y José Briceño (2009), el sector progresista de gobierno consideraba que el petróleo podía permitir una estrategia internacional de mayor independencia frente a Estados Unidos. También era favorable a la integración latinoamericana y caribeña, en la cual desempeñar un liderazgo.

Desde el punto de vista de las visiones dominantes en la política exterior, se evidencian dos importantes cambios: la mirada hacia América Latina y su papel en el contexto de la integración sudamericana.

Rafael Caldera (1994-1999), redefinió la estrategia de integración como parte de una revisión de la política exterior. El cambio se sustentaba en la nueva visión del país: Venezuela pasaba de mirar hacia la cuenca del Caribe para volcarse a América Latina y, 
principalmente a Sudamérica, proceso que finalizaría bajo Chávez con el ingreso de Venezuela al Mercosur. Las negociaciones se iniciaron durante su mandato, entre la Comunidad Andina de Naciones (CAN) y el Mercosur, pero fueron finalizadas entre Venezuela y el bloque sur-atlántico bajo el gobierno de Hugo Chávez.

El "viraje al sur" de Caldera se caracterizó por un fuerte apoyo a la cooperación e integración económica: fortalecimiento de la relación comercial con Colombia; creación de “Grupo de los Tres" (Venezuela, Colombia y México, 1994), inicio de las negociaciones para un ALC con Chile, fortalecimiento de la integración en el Acuerdo de Cartagena; acuerdos no recíprocos con Centroamérica y $\mathrm{CARICOM}^{23}$ y un mayor relacionamiento con el Mercosur; aunque finalmente Caldera respaldó la decisión de negociar un acuerdo entre los dos bloques regionales, la CAN y el Mercosur ${ }^{24}$.

Comparado con el período anterior -especialmente bajo el primer gobierno de C.A. Pérez, con una Venezuela proyectada a un marco mucho más global- Caldera restringe el activismo internacional a la región latinoamericana y caribeña. El camino elegido fue el perfil comercial. Serbin (1993) señala que el impulso al establecimiento de acuerdos de libre comercio y a la profundización de los esquemas de integración ya existentes se convirtió en una de las opciones fundamentales de la nueva política exterior.

\section{Las ideas y el pensamiento de Chávez}

Los grandes cambios en los criterios ordenadores de la política exterior vendrían con Hugo Chávez y, posteriormente, con Nicolás Maduro (Aranda, 2013; Serbin, 2010; Corrales, 2009; González Urrutia, 2008). ${ }^{25}$

Chávez se distanció de los paradigmas que orientaron la diplomacia venezolana a partir de los años 1960; distanciamiento continuado por Maduro. De ser un país en el cual la acción internacional jugaba un papel constructivo -bajo las ideas de convivencia con las naciones, articulación de iniciativas a favor del equilibrio internacional, defensa de la libertad y la democracia, consolidación de la integración e iniciativas en la búsqueda de la paz internacional- se pasó a desarrollar una estrategia con un marcado perfil ideológico, orientada a la construcción de una nueva geopolítica mundial y la búsqueda de mayor liderazgo mundial, que contrastaba con la visión precedente, en la cual, según Serbin (2010) y Romero (2007; 2005), no hubo búsqueda de confrontar con Estados Unidos.

\footnotetext{
${ }^{24}$ Alejandro Gutiérrez, "Venezuela: estrategia de desarrollo, política exterior, Patrón de comercio y el ingreso al MERCOSUR", en Noemí Mellado (coord. y ed.), Estrategias de inserción internacional e integración latinoamericana en el siglo XXI, Córdoba, Lerner Editora S.R.L. 2015.

${ }^{25}$ A pesar de la afirmación de Aranda (2013) de que no existe acuerdo académico acerca de si la política exterior del gobierno de Chávez fue rupturista o de continuidad con reformas, ya que se habría tratado de una experiencia que combinó ciertos aspectos materiales de la tradición dominante venezolana con la implementación de nuevas estrategias en su despliegue. Esta afirmación pone especial atención al uso del petróleo como el principal instrumento diplomático para promover los intereses venezolanos y que fue una constante estratégica desde los años 1940 hasta la desaparición de Chávez, ya que con éste el petróleo fue la clave económica y financiera de su estrategia política de integración y atracción, tal como han afirmado en sus estudios Gutiérrez (2015) y Silvia Quintanar (2012; 2012a).
} 
La crisis que conduce a la destitución de C.A. Pérez, los intentos de golpe de Estado liderado por Chávez y la posterior elección de éste como presidente, no pueden desligarse de la crisis general que afectó a la región, como consecuencia de la implementación de políticas económicas neoliberales de ajuste, desregulación de los mercados financieros y laborales, privatizaciones, retiro del Estado de sus obligaciones sociales, educativas, de salud y de previsión, que con diversos grados de profundidad se aplicaron según los países, desde México a la Argentina. La llegada de Chávez, así como la de otros presidentes identificados en la literatura en general como "progresistas", "populistas" o "de izquierda", como Lula (Brasil), Néstor y Cristina Fernández de Kirchner (Argentina), Correa (Ecuador), Morales (Bolivia), Vázquez (Uruguay) y Lugo (Paraguay), no puede ser entendida sin considerar el contexto de crisis, cuyo origen estuvo en lo que se denominó como "la década perdida", frente a la cual las políticas neoliberales fracasaron como respuesta. Desde entonces comenzaron a advertirse profundas diferencias entre las políticas -internas y externas- seguidas por los países (Bernal-Meza, 2012; Bernal-Meza and Christensen, 2012).

\section{a) El inicio del cambio radical en política exterior}

La conversión de Venezuela en un polo de poder regional y la integración política y económica de Latinoamérica con el fin de poseer un frente propio en el mundo globalizado estaban entre las primeras propuestas del equipo de gobierno del $\mathrm{MVR}^{26}$ (López-Portillo, 2008). Sin embargo, aunque Chávez le imprimió un sello particular a la política exterior, ciertos rasgos de ésta, del llamado puntofijismo, habían permanecido; como la idea que Venezuela debía cumplir un papel importante en el sistema internacional y en la región, cuya primera expresión había sido la doctrina Betancourt, que convirtió al país en un defensor de las democracias representativas ${ }^{27}$.

La relación de Chávez con América Latina y el Caribe, que serían sus primeros -y también más permanentes- objetivos internacionales (también posteriormente con Maduro, aunque irían perdiendo fuerza rápidamente al aumentar el deterioro económico y político del régimen) tiene su correlato interno en las transformaciones vividas por Venezuela.

La elección de Chávez (1998), los cambios introducidos en el sistema político (nueva constitución en 1999) y la instauración de nuevos mecanismos políticos como la Asamblea Nacional unicameral, se asociaron con cambios significativos en la política exterior del país, en temas y objetivos prioritarios; fuertemente signados por una visión ideológica radicalizada, en relación a lo que entonces se vivía en la región América LatinaCaribe (con la excepción de Cuba) y la progresiva reivindicación de una orientación bolivariana de la integración de los pueblos del continente. Simultáneamente, Chávez se movió con un estilo muy activo, de alta visibilidad (especialmente mediática) y que tendría siempre mucha repercusión internacional.

${ }^{26}$ El Movimiento Quinta República o MVR, fue el partido político que fundó Hugo Chávez, en 1997. Posteriormente, en el año 2007 el partido fue disuelto para integrar el Partido Socialista Unido de Venezuela PSUV, que gobierna hasta el presente.

${ }^{27}$ Tal como afirma Martha Márquez R. (2014). 
Chávez fue construyendo un discurso internacional sostenido en la visión del mundo de la llamada "revolución bolivariana" y que se sustentaba en una re-conceptualización o actualización sui generis del pensamiento de Bolívar. Se trató de una construcción ideológica que comparten aún otros presidentes de la región, como Rafael Correa (Ecuador), Evo Morales (Bolivia) y Daniel Ortega (Nicaragua), conocida como bolivarismo o bolivarianismo ${ }^{28}$. Según su impulsor, ésta se basa en las ideas de Bolívar, las que se supuso podían sostener un "socialismo del siglo XXI", es decir post caída del socialismo real; en tiempos de hegemonía de Estados Unidos y de globalización.

Chávez leyó a Bolívar influido por el pensamiento de la izquierda latinoamericana de los años sesenta y sobre la cosmovisión con la que el gobierno castrista enfrentó el mundo para defender su propia revolución, en particular sobre el papel que el poder militar jugaba en las relaciones internacionales como instrumento para proyectar la política nacional y defender sus propios proyectos nacionales.

El oportunismo de esta visión no puede soslayarse si se quiere mirar en perspectiva sistémica la proyección de intelectual de Chávez. En un mundo que se quedaba sin una ideología contestataria para enfrentar la dominación global del capitalismo, desaparecido el "socialismo real" y frente a la dominación del discurso ideológico que asociaba la caída de la Unión Soviética con el fin de la historia, Venezuela le aportaba a la causa de los países y pueblos explotados un nuevo discurso de lucha desde el Sur.

Esas ideas -antiimperialismo, anticolonialismo- estaban contenidas en los escritos del Libertador - la Carta de Jamaica, el Discurso de Angostura y el Manifiesto de Cartagena- producidos durante su campaña libertadora. La figura del Libertador proveyó las imágenes, internas y externas que asemejaban a Chávez con aquél. Así, "el cronotopo bolivariano confiere a Chávez una representación del mundo que orienta su acción política”, afirman Aranda y Salinas (2013). Sin embargo, es fundamental tener presente también la imagen muy negativa que Chávez tenía de los gobiernos norteamericanos (y particularmente de George Bush Jr. Y su intervencionismo); de los impactos que la etapa de hegemonía imperial posterior al fin de la guerra fría estaban teniendo sobre las sociedades latinoamericanas por la expansión del capitalismo monopólico, y sus visiones extremadamente críticas sobre el sistema de Bretton Woods, así como respecto de paradigmas de integración como el "regionalismo abierto", que promovían el libre mercado y, en definitiva, la continuidad de la especialización internacional.

El "ideal bolivariano", como plataforma ideológica, incubado a principios de la década de 1990, sería la fuente esencial del pensamiento internacional de Chávez. El bolivarianismo actuaría como un doble rechazo. Aranda y Salinas (2013a ) sostienen que el Presidente, por una parte rechazaba a las elites nacionales y, por otra, se oponía al marco internacional dominado por lógicas económicas liberales. Paradójicamente, como reveló López Portillo (2008), en el imaginario en el cual Chávez fue construyendo su mirada del

\footnotetext{
${ }^{28}$ Raúl Bernal-Meza (2009) y Aranda y Salinas (2013) han hecho referencias a la duplicidad de nombres con que se conoció la doctrina.
} 
mundo, "su libro de cabecera es el esotérico El oráculo del Guerrero, del escritor chileno Lucas Estrella, donde se plasman las enseñanzas del budismo zen" 29.

\section{b) Evolución de las ideas y la política}

La política exterior se fue formulando y desarrollando por etapas. A partir de 1999 y hasta la muerte de Chávez, Venezuela asumió un fuerte protagonismo en el escenario internacional. Según Morales (2008), desde 1999 se identificaron tres momentos en esta evolución; primero, una etapa de elaboración y declaraciones, con ciertos giros novedosos; después de las redefiniciones observables durante la cuartelada mediático-militar, se produce una etapa de reafirmaciones y reformulación de principios así como una recomposición del servicio exterior, que desembocó en una aceleración de una nueva proyección internacional en sus estrategias, alianzas y confrontaciones destinadas a incidir en el orden internacional hegemónico de la postguerra fría. Según este mismo autor, los enunciados de la nueva Constitución (1999), dejaban ver el empeño por modificar las perspectivas internacionales de Venezuela y sentaban las bases para ese cambio. "La nueva línea implementada por Chávez dejó ver varios desafíos de notable importancia a los poderes mundiales: formular sus políticas sin orientarse por el meridiano de Washington; implementar la reanimación de la OPEP (...); establecer una alianza con el proceso revolucionario cubano (...); impulsar una integración diversa a la Iniciativa de las Américas instrumentada por Estados Unidos para refuncionar sus intereses en esta nueva era de globalización" (Morales, 2008, p. 65).

La nueva etapa de la política exterior se inició luego del triunfo de Chávez en el referéndum revocatorio de agosto de 2004, que constituyó un momento de inflexión, que se expresó en la sustitución del esquema tradicional de inserción internacional de Venezuela. Así, según González Urrutia (2006, p. 165) la consolidación del proyecto revolucionario y la conformación de alianzas geopolíticas y estratégicas con otros países pasaron a ser los ejes centrales de la política exterior; aun cuando se mantuvieron ciertas tendencias estructurales de la conducta externa de administraciones previas. No obstante, es a partir de este momento que aparece el discurso "anti-imperialista" y "anti-capitalista" (Briceño Ruiz, 2011).

A partir de este momento y hasta 2007, el pensamiento de Heinz Dieterich, desarrollado en Socialismo del Siglo XXI (2002) $)^{30}$, quien formula el "Nuevo Proyecto Histórico", está en la base del pensamiento internacional de Chávez, quien comienza a plantear en su discurso internacional la construcción de un "bloque regional de poder". Según Dieterich, el nuevo proyecto histórico: Democracia participativa (socialismo), siglo $X X I$, permitiría avanzar en la fase de transición al nuevo socialismo.

Más tarde, se produce la ruptura de Chávez con el pensamiento del sociólogo alemán y la "revolución bolivariana" no seguirá más los lineamientos de la "teoría del

\footnotetext{
${ }^{29}$ Libro editado por editorial Cuatro Vientos, Santiago, en 1996, y publicado posteriormente por Grijalbo de México. El autor en realidad es argentino, aunque reside en Santiago de Chile.

30 Heinz Dieterich Steffan (2002), Socialismo del Siglo XXI, http://llibertatsolidaria.pangea.org/El_Socialismo_del_Siglo_XXI.pdf. Visitado el 10 de marzo de 2015. 
socialismo del siglo XXI". A partir de entonces se advierte un retorno con fuerza al pensamiento de Bolívar, que nunca había sido dejado de lado totalmente. No obstante, la referencia al "socialismo del siglo XXI", identificándolo como una construcción eidética propia, está en las palabras que Chávez pronuncia en el Foro de Porto Alegre (2001), al hablar de un "socialismo nuevo, con planteamientos frescos, acoplado con una nueva era que recién comienza. Por eso me atreví a llamarlo socialismo del siglo XXI, como proyecto" (Cabieses, 2005).

Los principios que sustentan en general la política del Estado derivan de la doctrina de Simón Bolívar, lo que está establecido por la propia Constitución. ${ }^{31}$ Uno de los rasgos más visibles de su proyección a la política exterior está en la utilización de una dialéctica de confrontación con aquellos países que considera sus adversarios, lo cual, según González Urrutia (2008), generó un clima de animosidad sin precedentes en las relaciones internacionales contemporáneas de Venezuela.

A los tres rasgos del pasado (excepcionalismo, presidencialismo, activismo), se agregaron con Chávez una visión geopolítica e ideológica del sistema internacional, con contenidos militaro-defensivos y de confrontación (que luego confluirían en la idea del "conflicto permanente"); la influencia del modelo cubano -de país pequeño y alto protagonismo internacional-, y la visión bolivariana (mesianismo, caudillismo y liderazgo de Venezuela), en la región y los proyectos de integración. Se advierte en ello la influencia de su formación militar, con una visión estratégico-militar de las relaciones de poder entre las naciones, la percepción sobre lo factible de una intervención externa y la amenaza del imperialismo (Serbin, 2010). El giro más radical, con un discurso "anti-imperialista" y de lucha "anticapitalista", aparece, como ruptura a partir de 2004 (Briceño Ruiz, 2011), donde las fuentes del pensamiento marxista, a través del pensamiento de Dieterich parece imponerse a la visión más "latinoamericana" -bolivariana- del pensamiento revolucionario. La visión pesimista que Chávez tenía sobre la globalización, contribuyó al desarrollo de las ideas sobre la necesidad de construir alianzas con gobiernos y movimientos sociales y políticos de otros países, afines a su visión ${ }^{32}$. Bajo esa red, tanto Chávez como Maduro buscarían dar respuesta crítica y combativa a la globalización neoliberal, desarrollando "una doctrina y una práctica anti-estatus heredada del Tercermundismo y de la cooperación Sur-Sur (Romero, 2016).

\section{c) Las influencias estructuralistas-dependentistas y castristas}

Chávez, influido por la concepción internacional de la guerra asimétrica de Fidel Castro, tenía una visión estratégico-militar de las relaciones de poder entre las naciones,

31 "La República Bolivariana de Venezuela es irrevocablemente libre e independiente y fundamenta su patrimonio moral y sus valores de libertad, igualdad, justicia y paz internacional en la doctrina de Simón Bolívar, el libertador"; Constitución Oficial de la República Bolivariana de Venezuela, Gaceta Oficial Extraordinario (5,453), Caracas, 24 de marzo de 2000, p. 3.

${ }^{32}$ Heinz Dieterich tenía una visión profundamente crítica del capitalismo en la fase de "globalización” y una pesimista visión sobre ésta, que seguramente influyó en la de Chávez; cfr. Noam Chomsky y Heins Dieterich, La Sociedad Global. Educación, Mercado y Democracia, México D.F., Editorial Joaquín Mortiz, 1995. 
una percepción de la intervención externa posible y el retorno al hemisferio del imperialismo norteamericano; con una fuerte influencia del pensamiento de la izquierda latinoamericana de los años de 1960 y una visión simplista y maniquea del sistema internacional que dividía entre buenos y malos; afirmación que sostienen Aranda (2013), Serbin (2010) y Bernal-Meza (2009). El tema militar ocupó un lugar importante en la reconfiguración de la proyección externa de Venezuela; situación que, según Morales (2008), se habría profundizado a medida que Estados Unidos perdía presencia militar en la región, después de la salida del Comando Sur de Panamá.

La experiencia cubana, que correspondió a un período de "guerra fría" latente, en particular durante los gobiernos norteamericanos más agresivos en contra de Cuba, aportó a Chávez dos elementos: 1) la necesidad de desarrollar una capacidad militar, dentro de una visión estratégica global; para enfrentar los desafíos y amenazas provenientes de Washington y sus aliados 2) la necesidad de desplegar un referente ideológico; con apelación a la equidad, solidaridad y justicia internacional, desde una perspectiva nacionalista, que encontraban su sustento en el pensamiento de los próceres libertadores en el caso de Venezuela el bolivarianismo- como la fuente de las coincidencias y aspiraciones de los pueblos latinoamericanos y caribeños.

Según Corrales y Romero (2013, p. 75) "La política exterior bolivariana y la seguridad y defensa se fundamentan en la tesis de la guerra asimétrica, entendida ésta como la puesta en práctica de una política defensiva social-militar del país ante cualquier agresión que se calificara como tal, dentro de la idea de una supuesta correlación entre el enemigo externo y el enemigo interno", que diseñó Chávez y cuyas ideas ha mantenido Maduro.

Esta visión, confrontacionista, desplazó a la que fuera tradicional en las ideas venezolanas, identificadas con la cooperación internacional, la promoción del intercambio comercial y de acuerdos e integración basados en el libre comercio; pero también se alejó radicalmente de las posiciones gubernamentales venezolanas anteriores más inmediatas, como la adhesión al "consenso de Washington".

La estrategia de construir un mundo multipolar partía de premisas como: articulación de nuevos polos geopolíticos de poder, la definición de nuevos mecanismos de integración, el afianzamiento de intereses políticos comunes, la internacionalización de la variable energética, la construcción de nuevos esquemas de cooperación económica y financiera, el desarrollo de una plataforma mundial de formación política dirigida a los movimientos sociales, académicos y políticos que compartían la visión del proyecto bolivariano y que podían generar apoyos al proceso. Esta política quebrantó muchas veces el principio de no injerencia en los asuntos internos de otros países, pues se trató de una política que se manejaba con criterios particularmente ideológicos ${ }^{33}$.

En este marco, la "diplomacia de los pueblos" "34, que Chávez adoptó de Evo Morales ${ }^{35}$, justificaba el relacionamiento ya no de "gobierno a gobierno" o de país a país", como lo

\footnotetext{
${ }^{33}$ Narvaja de Arnaoux (2008).

${ }^{34}$ Esta nueva interpretación de la diplomacia fue plasmada en las bases de la política exterior del Estado Plurinacional; formuladas en el Plan Nacional de Desarrollo "Bolivia Digna, Soberana, Productiva y Democrática para Vivir Bien: Lineamientos Estratégicos, 2006 - 2011”, en septiembre de 2007. Se señalaba que ésta se sustenta en cinco pilares fundamentales, el primero de los cuales hacía referencia directa a esta
} 
leía la diplomacia tradicional westfaliana, sino también el relacionamiento de un gobierno con comunidades sociales, sindicales y políticas de otro Estado, sin pasar por la intermediación del gobierno de ese o esos países.

Chávez reafirmó su protagonismo como contraparte de lo que interpretó como la nueva aspiración hegemónica de Estados Unidos. Al mismo tiempo, estableció una diferenciación ambigua, pues mantuvo una relación comercial estable con aquel que definía como el promotor de la globalización neoliberal que obstaculizaba la autonomía de la región y el desarrollo de un mundo multipolar. Pero esta ambigüedad fue también de Estados Unidos: una relación económica bilateral fluida y por otra participar en acciones que buscaban impedir la permanencia de Chávez en el gobierno.

\section{d) Las ideas sobre la integración latinoamericana}

A pesar de lo que se ha señalado precedentemente, la vertiente "latinoamericana" de las ideas de política exterior de la Revolución Bolivariana no se diferenció de las ideas de la política exterior precedente, pues mantuvo el interés que gobiernos anteriores habían manifestado por la integración y la cooperación regionales. Venezuela había sido clave para la creación de acuerdos de cooperación e integración económica y política, como el Grupo Andino (1969) y el SELA (1975), aunque con un perfil ideológico distinto. Ahora la influencia del pensamiento cubano -y la imagen de Castro- pasaban a ser muy importantes en el imaginario político que Chávez deseaba proyectar en la región. Según Romero (2010) el planteamiento de un bolivarianismo regional y de un antiimperialismo mundial sirvió de apoyo para un discurso anti-liberal en contra de la hegemonía estadounidense, a fin de mermar su poder. Esta propuesta significaba un reto para los países miembros de la CAN y del MERCOSUR y en especial para Brasil, que no tenían entre sus objetivos de política exterior la confrontación directa con Washington. Pero otro elemento sería muy relevante para los acontecimientos posteriores de las relaciones entre América Latina y Caribe e, incluso, con posterioridad, para el acercamiento de Estados Unidos: el retorno de Cuba al ámbito hemisférico, de la mano de Venezuela.

Silvia Quintanar (2012) afirma que la conformación de una alianza internacional que luchara contra la expresión del monroísmo en el siglo XXI, que Chávez identificó con el proyecto ALCA, se proyectaría en América Latina a través de la creación de la Alianza Bolivariana de los Pueblos de Nuestra América (ALBA); el proyecto de integración hemisférico antiimperialista, anticolonialista y antiliberal.

nueva praxis internacional: Diplomacia de los pueblos, que busca escuchar, dialogar y trabajar para todos; anteponer los intereses de la nación a los de un sector y anteponer los principios de la vida a la lógica de mercado.

${ }^{35}$ La relación entre Evo Morales y Chávez fue muy importante. Ambos se influyeron mutuamente. Morales adhirió a la visión de Chávez de crear alianzas internacionales contra-imperialistas y contra-hegemónicas (cuyo ejemplo más claro fue la relación que Morales estableció con Irán; entonces un enemigo clave de Estados Unidos), mientras Chávez adoptó la “diplomacia de los pueblos”, formulada por Morales, como uno de los instrumentos de vinculación internacional.

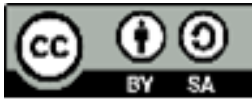


Hasta aquí, pueden observarse dos elementos: el primero, es el rescate del pensamiento de Bolívar como fuente de sustentación de la política internacional; el segundo, el papel articulador y hermanador e integrador que la figura de Bolívar proyectaba sobre los pueblos de varios países: Ecuador, Bolivia, Colombia y de la propia Venezuela.

La idea de una "Comunidad de Naciones Latinoamericanas y Caribeñas" es explícita en su vínculo con el pensamiento de Bolívar. Los procesos de integración son vistos como fundamentos para la construcción de la unidad latinoamericana. La "Comunidad de Naciones Latinoamericanas y Caribeñas" se contrapone en los discursos de Chávez con la amenaza económico-militar proveniente del Norte, específicamente, del imperialismo norteamericano, frente a la "unión natural" de las naciones latinoamericanas y caribeñas (Narvaja de Arnaoux, 2008).

La visión de la integración -en los distintos esquemas que Chávez impulsó, como ALBA, o en los que se incorporó (UNASUR, Mercosur)- mantuvo siempre una posición de rechazo al libre comercio. Procuró la conformación de un "bloque latinoamericano de poder" que condujera a una nueva institucionalidad que, en lo político, estuviera basada en la concepción de la democracia participativa, de inclusión de los pueblos y su participación activa en mecanismos internacionales. Su idea era proyectar nuevamente a la región como una unidad, frente al Occidente desarrollado. Sin embargo, sus iniciativas de integración mantuvieron el perfil intergubernamental que ha caracterizado a todos los acuerdos de integración vigentes en la región, en los cuales la participación ciudadana y social queda subsumida en las ideas y la voluntad de los presidentes y jefes de gobierno.

ALBA y UNASUR se inscribieron en la estrategia para desmarcarse de la visión capitalista y neoliberal de la economía y permitían mantener la confrontación con EE.UU. En ese mismo contexto se sustenta su rechazo a las negociaciones comerciales entre la CAN y la Unión Europea para un acuerdo de libre comercio, como previamente había rechazado la adhesión al "consenso de Washington" que habían manifestado diversos gobiernos latinoamericanos desde los años de 1990.

Venezuela asumió un rol de contrapeso en la visión de la integración latinoamericana y caribeña, desde una perspectiva que privilegiaba lo militar y lo político por sobre lo económico-comercial y la cooperación tradicional, aun cuando para ello utilizara instrumentos económicos y financieros muy importantes, como el petróleo y la ayuda financiera; pero éstos no eran el objetivo, sino sus medios.

\section{e) Chávez y las polarizaciones}

Chávez profundizó la polarización social en Venezuela y la transformó en polarización geopolítica, que intentó proyectar al Caribe, a los países andinos y al Cono Sur. A partir de un discurso maniqueo, que separaba entre buenos y malos, logró dividir su entorno regional cercano en dos polos enfrentados: de un lado, los revolucionarios bolivarianos y sus aliados en distintos países, cuyo liderazgo buscó asumir, y del otro, las élites aliadas, de distintos países (incluyendo el suyo) con los intereses de Washington y las corporaciones. Como resultado, la presidencia de Chávez se convirtió en el gobierno más 
polarizado de Venezuela desde finales de la década del 40 y de América Latina desde el gobierno sandinista de Nicaragua en los ochenta (Serbin, 2010; Romero, 2007; González Urrutia 2006).

Chávez apuntaba a la creación de "nuevos polos de poder mundiales", en un intento por provocar el debilitamiento de la hegemonía del "imperialismo norteamericano", en cuya estrategia la variable energética desempeñaba un papel fundamental. No era sólo el aporte económico-energético y financiero que brindaba el petróleo, sino también el hecho que las potencias occidentales eran dependientes de este energético y aquí manifestaban una de sus escasas debilidades estructurales.

La dialéctica de confrontación puso a la construcción de alianzas en un lugar relevante. Entre los diez objetivos de un taller de alto nivel, que Chávez promovió después del triunfo en el referéndum revocatorio de 2004, figuró "Seguir impulsando el nuevo sistema internacional multipolar". En este marco Chávez enumeró, en función de una política exterior basada en las prioridades geopolíticas, cinco polos de poder en el mundo -Europa, Asia, África, Norteamérica y Sudamérica- y planteó, para la época y a nivel regional, la conformación de dos ejes contrapuestos, por un lado, el eje Caracas, Brasilia y Buenos Aires y, por otro, Bogotá, Quito (antes de Correa), Lima y Santiago de Chile; este último eje dominado, según su percepción, por el Pentágono, en el entendido de que los gobiernos de Lula Da Silva y de Néstor Kirchner y luego de Cristina de Kirchner, se alineaban con su posición antiestadounidense.

Sin embargo, en el caso de la confrontación con Estados Unidos, es muy posible que la llegada al gobierno norteamericano de George Bush Jr. haya sido el disparador de la radicalización anti-norteamericana y que los intentos del presidente norteamericano por deponer al mandatario venezolano hayan impulsado $y$ fortalecido su antinorteamericanismo. Morales (2008) cita afirmaciones de Eva Gollinger ${ }^{36}$, quien demostró, mediante documentos desclasificados, que el gobierno de Washington financió y alentó a la oposición interna con ese propósito.

\section{f) Petróleo, integración y liderazgos: los enfrentamientos con Brasil}

Chávez tuvo en Carlos Andrés Pérez un ejemplo y antecedente de la utilización del petróleo como instrumento diplomático y de política exterior. Como describe Gamuz (1989) es importante destacar el lugar especial ocupado por el petróleo durante el período de gobierno de Pérez, porque la coyuntura de crisis energética y de elevados precios del petróleo permitieron a Venezuela incrementar su poder de negociación con los países industrializados, gracias a su condición de importante país productor, en búsqueda de una nueva relación Norte-Sur y utilizarlo como un elemento importante de cooperación con los países del Tercer Mundo.

El Comandante Chávez utilizó la cooperación energética para integrar, en una red latinoamericana, a Caribe, América Central, la comunidad andina y el Mercosur, cuyo

${ }^{36}$ Eva Gollinger, El código Chávez: Descifrando la intervención de los Estados Unidos en Venezuela, Caracas, Monte Ávila Editores Latinoamericana C.A., 2005.

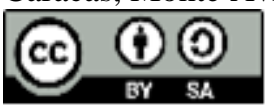


núcleo central fuera Venezuela. PetroCaribe, PetroAndina y PetroSur eran parte de la integración regional a través de PETROAMËRICA: un proyecto iniciado en 2003, destinado a crear una empresa multinacional, conformada por empresas estatales de petróleo de la región, propuesta que sería aceptada por la Comunidad Sudamericana de Naciones en septiembre de 2005 (Quintanar, 2012a). Argentina, que por entonces no tenía una empresa estatal de petróleo, puesto que YPF había sido privatizada por Menem durante la década anterior, creó Enarsa, para acoplarse a la idea de asociar a los tres grandes países de la región a través de la matriz energética: Venezuela, Brasil y Argentina.

La idea no era nueva en la región; ya a finales de la década de 1980 Helio Jaguaribe había propuesto la creación de una gran multinacional latinoamericana, integrada por Petrobras, Pedevesa e $\mathrm{YPF}^{37}$. Pero sería Chávez, enfrentando a Brasil, el que plantearía la integración regional energética, y en general toda integración, como un asunto de los Estados y no de los privados (Bernal-Meza, 2010).

Pero los tiempos eran otros. Ni Brasil ni Chile estuvieron de acuerdo en dejar en manos de empresas estatales la integración estratégica sudamericana del petróleo, aunque por razones distintas. Sin embargo, no fueron sólo las diferencias en las estrategias energéticas, las que enfrentarían a Chávez con Lula, sino también la visión sobre la integración sudamericana posible. A esas diferencias se agregaron las críticas de Chávez al modelo de integración del Mercosur, que asociaba con el libre comercio y la promoción del capitalismo y las críticas al programa de integración en infraestructura regional sudamericana (IIRSA), impulsado por Cardoso en el año 2000 y que Lula da Silva había decidido continuar, como una cuestión estratégica para la conexión de Brasil con Sudamérica $^{38}$. Más tarde Chávez cuestionó el desarrollo de la industria de biocombustibles, en la cual Brasil comenzaba a ser líder mundial. En el fondo, se trataba de una disputa por el liderazgo sudamericano. Como señaló Duarte Villa (2013, p. 249),

"os governos do presidente Chávez têm mostrado uma capacidade de iniciativa diplomática e económica que se chocam bastante com as aspirações brasileiras de liderança sul-americana. Esse fato foi chave para o Brasil pasar a perceber que Hugo Chávez leva a sério o projeto de construção de uma liderança regional, e que, em perspectiva, tinha como vizinho não só um aliado, mas um concorrente potencial”.

\footnotetext{
${ }^{37} \mathrm{El}$ autor de este artículo se la escuchó a H. Jaguaribe, en un extenso análisis, en un seminario reservado, organizado por el centro de estudios de relaciones internacionales EURAL, en Buenos Aires. El prestigioso analista y académico brasileño proponía entonces la creación de una gran multinacional sudamericana, a la que podría integrarse también Pemex, con el fin de competir en el mercado mundial energético.

${ }^{38}$ El papel estratégico de IIRSA para Brasil fue analizado por Quintanar y López y más tarde actualizado por este último. Cfr. Silvia Quintanar y Rodolfo López, "La integración de la infraestructura regional en América del Sur (IIRSA) y el eje Mercosur-Chile", en Economía mundial y desarrollo regional, ed. Raúl Bernal-Meza y Suranjit Kumar Saha, Buenos Aires, Nuevohacer/Grupo Editor Latinoamericano, 2005), y Rodolfo López "Nuevo instrumento de regionalismo. Resultados de la Iniciativa para la Integración de la Infraestructura Regional Sudamericana (IIRSA)", en Regionalismo y Orden Mundial: Suramérica, Europa, China, 2012..
} 
En el fondo, de lo que se trató fue de una lucha por el liderazgo sudamericano, entre Chávez y Lula.

Petróleo e integración se unieron en el imaginario de Chávez y facilitaron sus proyectos regionales e internacionales. Sin embargo, su estrategia provocó convergencias y profundas divergencias en el seno del continente sudamericano, especialmente con Brasil gobernado por Lula, que no compartió su visión sobre la naturaleza, instrumentos y objetivos de la cooperación energética sudamericana (Quintanar, 2012a).

De allí que, según Morales (2008, p. 73) el éxito internacional más importante de Chávez fuera la resurrección de la OPEP, pues ella jugaba un papel de relevancia en la configuración de un orden multipolar y que la diplomacia petrolera fuera el eje de la recomposición de la cartografía geopolítica de la región y un pivote para un proyecto de integración diferente al promovido por Estados Unidos. Sin embargo, la visión de la integración latinoamericana que él proyectó a través de ALBA, no logró atraer a los países grandes -Brasil y México- y tampoco a los medianos de la región: Argentina, Colombia y Chile.

\section{Maduro y el reforzamiento de las líneas centrales de las ideas y el pensamiento en política exterior}

Bajo la conducción de Maduro, se produjo una renovación del pensamiento en política exterior $^{39}$. El Ministerio de Relaciones Exteriores de Venezuela publicó en 2012 un documento que resumía la doctrina y el marco teórico que sustentaba ahora la política exterior del país ${ }^{40}$; sin dejar de lado la tradición bolivariana iniciada y desarrollada por Chávez.

En ese documento se señalaba que las iniciativas estratégicas de la política exterior se concebían como un elemento clave que permitiría a Venezuela alcanzar lo que Marcelo Gullo (2010) denomina «umbral de poder»; es decir, un estadio de desarrollo que permite a un Estado superar la condición de periférico y por ende la de subordinado. Según el autor, el sistema internacional consta básicamente de estructuras hegemónicas de poder donde destacan Estados subordinantes y Estados subordinados. Cuando los últimos alcanzan el «umbral» de poder pueden volverse Estados subordinantes si su desarrollo industrial, además de la conformación de élites y cuadros políticos, va acompañado de una reflexión seria sobre la subordinación ideológica derivada de las estructuras hegemónicas de poder. Esta reflexión debe transformarse en «insubordinación fundante», es decir, una actitud emancipadora con respecto al pensamiento dominante; sólo si esto ocurre, el país en cuestión dejará de ser periférico (Gullo, 2010, p. 13-14). "La política exterior de la República Bolivariana de Venezuela debe estar orientada hacia el incremento de su

39 Cfr. El País on line. Venezuela adopta categorías conceptuales de Marcelo Gullo. http://elpaisonline.com/index.php/edicion-virtual/item/112548-venezuela-adopta-categorias-conceptuales-demarcelo-gullo. Visitado el 10 de enero de 2016.

${ }^{40}$ Cfr. Emancipacion de la política Exterior de Venezuela. Ministerio del Poder Popular para Relaciones Exteriores- Direccion de Planificacion Area de Planes Estrategicos y Operativos, Caracas, 2012. 
«umbral de poder»", señalaba Gullo. "La diplomacia blanda se perfila como una estrategia de arquitectura compleja, pues su objetivo central es la superación de nuestra condición periférica. Esto sólo puede materializarse a través de una consistente insubordinación ideológica frente a toda forma de dominación imperialista. En sí, la insubordinación ideológica representa la primera etapa del proceso emancipador de la Revolución Bolivariana" (p. 37).

El documento de política exterior de Maduro hacía suya la "Teoría de la insubordinación fundante" y utilizaría los conceptos de "umbral de poder", "Estados subordinantes y Estados subordinados", "insubordinación ideológica" e "insubordinación fundante" formulados por Gullo.

Desde estas perspectivas, las líneas de acción internacional de Venezuela marcarían la persistencia de la construcción de alianzas internacionales e instrumentos regionales, como ALBA. Esta visión, al tiempo que proyectaba en el tiempo las ideas de Chávez sobre el orden internacional, acerca de la necesidad de mantener y fortalecer dichas alianzas e instrumentos, le permitían a Maduro proponer y difundir ideas nuevas (como propias) que diferenciaban a su propia gestión internacional de gobierno.

\section{a) El reforzamiento del pensamiento estructuralista latinoamericano}

La formulación de Gullo -insubordinación fundante- tiene tres líneas de sustento teórico, las que también confluyen con las visiones de la "revolución bolivariana" y la actualización del pensamiento de Bolívar. Estas líneas son: el pensamiento estructuralista, porque hace referencia a la modelización centro-periferia. De hecho, el documento del Ministerio hacía referencia en diversos momentos a conceptos y categorías estructuralistas y de los enfoques de la Dependencia -como "centro" y "periferia", Estados subordinados o "periféricos"- lo que expresaba también la adscripción conceptual de la formulación de política y el propio discurso de la política exterior a la epistemología del estructuralismo latinoamericano. Finalmente, la formulación adscribía al realismo, porque hay en ella una visión hobbesiana del mundo, expresada en la utilización de categorías realistas vinculadas con el poder. Coincide así la formulación con la idea que fundamentó la construcción de alianzas internacionales de Chávez: "el poder ha sido y es la condición necesaria para atemperar, neutralizar o evitar la subordinación política y la explotación económica. (...) el poder es la condición sine qua non para garantizar la seguridad y neutralizar la codicia" (Gullo, 2010, p. 25) y la propia conceptualización de la insubordinación fundante hace referencia a la disposición a luchar contra el poder dominante ${ }^{41}$; coincidiendo así con el discurso de la política exterior bolivariana.

\footnotetext{
${ }^{41}$ Ésta se sostiene en tres hipótesis: 1) los Estados que se encuentran en la periferia de la estructura del poder mundial sólo pueden trocar su condición de "objetos" convirtiéndose en "sujetos" de la política internacional a partir de un proceso de insubordinación fundante; 2) en el origen del poder de los Estados está, generalmente, presente el impulso estatal, que es el que provoca la reacción en cadena de todos (los) elementos que componen, en potencia, el poder de un Estado; 3) todos los procesos emancipatorios exitosos fueron el resultado de una adecuada conjugación de una actitud de insubordinación ideológica hacia el pensamiento hegemónico y de un eficaz impulso estatal (Gullo,2010, p. 21).
} 


\section{b) La visión sobre el regionalismo y la integración}

Del pasado de una estrecha vinculación con México -en la creación del $\operatorname{SELA}^{42}$ y con Colombia -donde junto con México participaron de iniciativas políticas tan relevantes como el Grupo de Contadora (1983) y crearon el Grupo de Los Tres (1995) ${ }^{43}$ - todas iniciativas que expresaban altos niveles de convergencia política y económica entre estos países, Venezuela pasó a posiciones profundamente divergentes con éstos. Primero con Chávez, al impulsar la creación de ALBA y luego con la tenaz oposición de Maduro a la Alianza del Pacífico, que integran México, Perú, Chile y Colombia.

Las posiciones que enfrentarían a Venezuela con sus socios tradicionales estuvieron en las distintas visiones sobre el regionalismo y la integración, y por diferencias sobre las relaciones con Estados Unidos. Giacalone (2014, p. 41), sostiene que el regionalismo venezolano difiere del de la mayoría de los países sudamericanos que prefieren formas menos conflictivas de política exterior y de inserción internacional. ALBA fue creada casi simultáneamente a la Comunidad Sudamericana de Naciones (CSN). Sin embargo, la continuidad de ALBA demostró que ni la CSN ni su sucesora, la UNASUR, expresaron las ideas ni los intereses del regionalismo venezolano. Según Quintanar (2012) y Malamud y Giardini (2012), las divergencias entre ALBA y UNASUR se encuentran justamente en las relaciones con Estados Unidos: confrontación en ALBA, no conflictivas en UNASUR); competencia por los liderazgos: Venezuela en ALBA, Brasil en UNASUR, y las diferencias respecto del modelo de desarrollo y regionalismo. Mientras ALBA rechaza el regionalismo abierto y el libre comercio, UNASUR expresa un pragmatismo y flexibilidad que facilita la integración de distintos modelos de inserción económica. Justamente los factores clave buenas relaciones con Estados Unidos, regionalismo abierto y libre comercio- están presentes en la Alianza del Pacífico, lo que explica también que ésta se transformara para Venezuela, desde Chávez, en el objetivo más importante a combatir dentro del regionalismo latinoamericano.

\section{c) El ocaso. Realismo y pragmatismo cubano y cambios políticos en el escenario regional}

Desde la profundización de la crisis económica y política internas de Venezuela, la política internacional de Maduro se concentró esencialmente en su conflicto con Estados Unidos -país al que acusa de ejercer políticas y acciones destinadas a destruir su gobiernoel perfil internacional y regional de Venezuela perdió todo su vigor.

Las declaraciones de Evo Morales, con posterioridad a la elección presidencial de Mauricio Macri en Argentina, pusieron de relevancia el aislamiento regional que

\footnotetext{
${ }^{42}$ El Sistema Económico Latinoamericano y del Caribe (SELA) fue creado en octubre de 1975, como un organismo regional intergubernamental con sede en Caracas, cuyo objetivo fue promover mecanismos de consulta, coordinación y concertación de posiciones y estrategias en el ámbito de las relaciones económicas internacionales. Su primera significación la constituyó la reintegración de Cuba a un sistema regional, luego de la expulsión de la OEA en 1962.

${ }^{43}$ Que funcionó hasta 2006, cuando Venezuela lo abandonó para incorporarse al Mercosur.
} 
comenzaba a vivir el gobierno de Maduro. En una entrevista publicada por un diario argentino, Morales señaló que le dolía mucho ver el nuevo panorama político en la región y que él y su par venezolano, se sentían "solos", aunque "no asustados". 44

El escenario internacional que Chávez interpretó siempre de manera muy fina, comenzó a sufrir drásticos cambios para los que Maduro no pareció tener ideas de respuesta.

A pesar de los antecedentes que ponían a Raúl Castro a la izquierda de Fidel, el pensamiento cubano en política exterior profundizó su visión neorrealista e institucionalista, que ponía atención en los cambios mundiales que se registraban y en la necesidad de utilizar las instituciones internacionales a su favor. Como señala Domínguez (2009, p- 344-45), Cuba siguió en los 90 una estrategia de alianza con nuevas organizaciones internacionales y de adaptación a las organizaciones internacionales que no se encontraban dominadas por Estados $U$ nidos. Las organizaciones internacionales proporcionaron a Cuba una opción para hacer frente a Estados Unidos y romper su aislamiento. Cuba siguió también una estrategia institucionalista, en su contexto, por razones en las que convergen neorrealismo e institucionalismo. Las instituciones internacionales facilitan la transferencia de información, un activo valioso para un país aislado como Cuba ibid). La adscripción a una visión institucionalista de las relaciones internacionales le permitió encontrar nuevos socios después del fin de la guerra fría y "logró consensuar en la ONU una condena al embargo impuesto por Washington" (Serbin, 2016, p. 138). A diferencia, Maduro no haría nada de esto.

Si bien hasta 2013 la ambigüedad y un comportamiento pragmático fueron elementos que le permitieron a Chávez disfrutar de un espacio de maniobra internacional favorable (Romero, 2013), Maduro mantuvo claridad confrontativa y un comportamiento discursivo rígido, fiel a las ideas revisionistas de su política exterior. ${ }^{45}$

Según Mijares y Romero (2016) el aislamiento relativo de un gobierno que se siente asediado no mejora ante el escenario de reaproximación cubano-estadounidense. Por el contrario, la cada vez más diversificada diplomacia de La Habana parece poner más presión sobre los hombros de jerarcas chavistas que ven con alarma la contracción del mundo a su alrededor y tienden a aferrarse a sus actuales posiciones de poder. Sin embargo, el problema principal de Maduro -y en lo que se distanció profundamente de Chávez- es que no adoptó una orientación pragmática y no confrontacionista en la política exterior, que le hubiera permitido mantener el sistema político establecido por la Revolución Bolivariana y que la política exterior se mantuviera ajustada a sus principios y valores. ${ }^{46}$

\footnotetext{
${ }^{44}$ La Nación.cl, "Morales dice que se siente solo junto a Maduro en la región”, 11 de diciembre de 2015. http://www.lanacion.cl/noticias/mundo/bolivia/morales-dice-que-se-siente-solo-junto-a-maduro-en-laregion/2015-12-11/123842.html. Visitado el 10 de octubre de 2016.

${ }^{45}$ Es posible que el escenario interno, de radicalización social y política, bajo crisis económica, como consecuencia de la caída drástica de los precios internacionales del petróleo sean parte de la explicación de la radicalización y pérdida de pragmatismo, como argumentan Romero y Mijares (2016) y Serbin (2016). Dado que aquí analizamos las ideas y pensamiento no abordamos ese debate.

${ }^{46}$ En este sentido, Maduro no siguió el ejemplo cubano, cuyo pragmatismo le ha permitido mantener el sistema político-económico y los principios defendidos por la Revolución, tal como coinciden Domínguez (2009) y Serbin (2016).
} 


\section{Conclusiones}

Resulta evidente la importancia que el pensamiento en asuntos internacionales de sus gobiernos, durante el período de análisis (1990-2016) tuvo para la proyección internacional y regional de Venezuela, dada su condición de "potencia secundaria de la región", cuyos recursos petroleros le permitieron durante más de treinta años implementar estrategias y proyectos de regionalismo, integración y cooperación, dirigidos a América Latina y el Caribe.

La promoción de iniciativas y las aspiraciones de liderazgo venezolano, bajo la conducción de Chávez, llegarían a su fin con su desaparición física y la asunción del nuevo gobierno.

Pueden ordenarse algunos elementos clave que sostuvieron el pensamiento de la política exterior de Chávez: el papel estratégico que tenía el petróleo, que, en un contexto de escases y altos precios fortaleció la autonomía y capacidad financiera de Venezuela; la interpretación acerca del rol que el componente militar jugaba en las relaciones internacionales; un elemento que retomaba las percepciones de los años ochenta en Centroamérica, pero, especialmente, del marco de las relaciones bilaterales e internacionales entre Estados Unidos y Cuba desde 1960. La experiencia cubana le daba a Chávez el sustento histórico sobre cómo defender su revolución frente a las políticas imperialistas de Washington. Finalmente, el papel que jugaba la integración regional. Según Santana (2008), con la iniciativa de ALBA el presidente Chávez irrumpió en el escenario político a nivel internacional, modificando la perspectiva dirigida hacia el norte, pues logró consolidar el interés por una iniciativa integracionista latinoamericana y caribeña. A su vez, fortaleció la alianza entre Venezuela, América del Sur y el Caribe, objetivo que Caldera había impulsado anteriormente sin éxito. A diferencia de Carlos Andrés Pérez, que utilizó foros multilaterales para promover sus iniciativas y estrategias de cooperación sur-sur dirigidas a refundar las relaciones Norte-Sur (SELA, ONU. OEA, Movimiento de países No Alineados, etc.), así como internacionales políticas (internacional Socialista), Chávez utilizaría plataformas de países afines, como ALBA y la construcción de alianzas con gobiernos y movimientos y partidos políticos ideológica y eidéticamente afines a través del mundo.

Desde 1999 y hasta su desaparición física, Chávez impulsó una política exterior cuyas ideas centrales se asentaban en la política de seguridad y defensa, bajo una visión geopolítica y militar del sistema internacional, con un papel cada vez más importante de la presencia militar en el gobierno, muy influida por la idea de la existencia de un "conflicto permanente" en el sistema internacional contra el capitalismo y el imperialismo (Domínguez, 2009; Serbin y Serbin Pont, 2014; Serbin, 2016). La visión era congruente con el contexto internacional que facilitaba la difusión de esas ideas: período de altos precios del petróleo y otros commodities; difusión del poder global con el ascenso de China, Rusia y Brasil; rechazos internacionales a las intervenciones norteamericanas en Afganistán e Irak; rechazos internacionales a la "doctrina norteamericana del terror"; estrecha alianza entre Venezuela y Cuba (Romero y Mijares, 2016). Fue evidente que

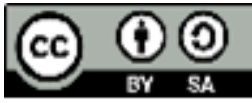


Chávez "leyó" e interpretó muy bien el escenario internacional para promover sus ideas y visiones de política exterior.

Venezuela mantuvo una fuerte proyección internacional de la figura presidencial, porque sus gobiernos -Chávez y Maduro- se caracterizaron como regímenes presidencialistas fuertes, en los cuales la figura del Jefe del Ejecutivo permitió proyectar su pensamiento y visión del mundo sobre la sociedad en su conjunto, plasmando sus ideas sobre la política exterior. Sin embargo, el activismo internacional no diferenció estos gobiernos de los del pasado. Desde 1959 Venezuela se había caracterizado por el activismo internacional y la promoción de proyectos de integración y cooperación. La diferencia estaba en el vínculo entre autonomía-desarrollo que el capitalismo deterioraba y la consiguiente necesidad de la lucha antiimperialista. Sin embargo, el enfrentamiento contra el capitalismo y el "imperialismo norteamericano" nunca fueron, antes de Chávez y Maduro, parte de las ideas de la política exterior venezolana y aquí se encuentra la gran ruptura histórica de la política exterior.

Considerando las macro visiones, paradigmas y concepciones de sí y del mundo recopiladas en el período de referencia, el pensamiento gubernamental venezolano se ha caracterizado por dos rasgos principales: 1) la variable continuidad-ruptura, en los ciclos 1990-1998 respecto del pasado, y el posterior, entre 1998 y 2016, respecto de su ciclo inmediatamente anterior, cuyo punto de inflexión está en la creciente radicalización de las ideas; 2) que la elaboración de interpretaciones sobre la inserción internacional fue, esencialmente, obra del Presidente, en el caso de Chávez, mientras que Maduro recurrió al sustento cognitivo de un autor argentino, que fue incorporado a la visión internacional heredada de Chávez.

Desde el punto de vista histórico, es posible referirse a cambios profundos en las imágenes y visiones internacionales, que se pueden identificar a partir del derrumbe del sistema político venezolano negociado en los Acuerdos de Punto Fijo, pero que se producen dentro del mismo tipo de régimen político. Venezuela reflejó continuidad con renovación, en el tránsito de los gobiernos de Chávez a Maduro.

En relación a los grandes ejes de la política internacional, Venezuela ha evidenciado en el período un esfuerzo por llevar a la práctica las ideas respecto de la formación de coaliciones en contra de Estados Unidos. Este hecho diferenció a Chávez y Maduro de todo el continente hispano-luso-americano durante el período y también respecto de la propia política exterior venezolana anterior.

Sin embargo, el pragmatismo también estuvo presente. Se vio reflejado en la participación del país en acuerdos de integración y regionalismos que no le satisfacían, como Mercosur y UNASUR, mientras, por otra parte, impulsaba su propio modelo de regionalismo -ALBA- que nunca consiguió adherir a otras "potencias secundarias" para enfrentar a la región contra Estados Unidos y sus aliados regionales. A pesar que Chávez tuvo una estrecha relación política y económica con los gobiernos argentinos del período 2003-2015, compartiendo críticas a Washington y al liberalismo económico y de haber coincidido con la potencia regional (Brasil) y otros países de menores recursos de poder como Ecuador y Bolivia- en el rechazo a las iniciativas de integración económica

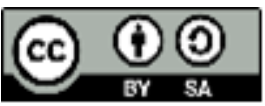


promovidas por Estados Unidos (ALCA), Chávez fracasó en su objetivo, porque poderes secundarios claves en la región no se subordinaron a su visión ni liderazgo.

Chávez -y luego Maduro- se mantuvieron dentro de UNASUR y el Mercosur. Esta posible contradicción podría explicarse por la necesidad regional de concertar, con pragmatismo y flexibilidad, con el objetivo de más largo plazo: construir el modelo de integración política y económica latinoamericano y caribeño a la que aspiró Chávez siguiendo el sueño de Bolívar. En ese sentido, el retorno de Cuba a la comunidad latinoamericana, integrando CELAC, fue un importante logro de Chávez, que seguía la línea de C.A. Pérez, cuando había incorporado a Cuba al nuevo mecanismo de concertación regional: el SELA. Un elemento más que nos permite afirmar la existencia de "rupturas dentro de grandes continuidades" en la política exterior de Venezuela.

En el pensamiento venezolano bajo los gobiernos conducidos por Chávez y Maduro, se pueden identificar tres etapas: la influencia del pensamiento de Dieterich, la descripción de lo que Chávez identifica como el "socialismo del siglo XXI" y la influencia del pensamiento de Gullo; aun cuando la línea que da sustento a todo el período está en las reflexiones anti-monroístas y antiimperialistas de Bolívar. Sin embargo, los contenidos anti-sistémicos, anti-imperialistas y anti-norteamericanos que movían la acción internacional de la política exterior se abandonaron con Maduro: la búsqueda de la construcción de un sistema "multipolar" y de un eje de alianzas y bloques internacionales y regionales (integración solidaria). Ello puso de manifiesto no sólo la debilidad del liderazgo internacional de Venezuela en esta etapa del país, sino también la ausencia de una claridad estratégica para construir esa insubordinación fundante.

El activismo internacional no continuó bajo Maduro en la misma dimensión global ni regional. Las nuevas ideas incorporadas no permitieron la expansión de la política exterior. Romero y Mijares (2016) sostienen como hipótesis que las corrientes históricas de la fragmentación socio-política, las tensiones regionales y el mercado de la energía, plantearon dificultades para la continuación de una política exterior expansiva, pero a su vez actuaron como un estímulo para una mayor centralización del poder interno, y la politización de la agenda de la política exterior, de acuerdo con los objetivos y las tendencias generales del partido de gobierno.

El Comandante fue pragmático al aceptar la coexistencia de modelos de regionalismo que consideraba opuestos a su visión; que no enfrentaban al capitalismo y a la visión norteamericana de la integración; incluso se integró a uno de ellos (Mercosur). También fue pragmático al aceptar que UNASUR fuera una instancia amplia y flexible de temas, agendas y debates. Esto le permitió mantener simpatías y evitar rechazos por parte de gobiernos ideológicamente distintos y pudo mantener sus alianzas regionales sin despertar mayores resentimientos. No ha sido el caso de Maduro, quien no abandonó la retórica asociada al enfrentamiento autonomía v/s aceptación de la hegemonía norteamericana, en un tiempo en que su principal aliado - Cuba- comenzaba a privilegiar la normalización de relaciones con los Estados Unidos y a aggiornar y actualizar su discurso internacional pero sin abandonar las ideas. Maduro mantuvo la idea central acerca del conflicto permanente con el capitalismo y el imperialismo, pero no ha aplicado una visión pragmática en la política exterior que le permitiera mantener las ideas, valores y principios 
defendidos por la Revolución Bolivariana en un momento en que las condiciones internacionales -recomposición de las relaciones Cuba y Estados Unidos- e internas drástica caída de los ingresos petroleros, crisis económica- se modificaban drásticamente, y en esto se alejó de la experiencia de Chávez.

Maduro radicalizó el discurso y las ideas y persistió en la visión del conflicto permanente cuando el escenario se estaba modificando, no sólo en la relación entre su aliado y su enemigo, sino por la desaparición de gobiernos que lo habían respaldado en parte o coincidido con él en ciertas críticas a la política exterior norteamericana, como fueron los gobiernos de Mujica, Kirchner, Lula, Fernández de Kirchner y Dilma Rousseff y se enfrentó a los que les sucedieron. Pero también han desaparecido las alianzas extraregionales que construyó Chávez: Argelia, Irán, Libia; mientras para su sorpresa, Cuba recomponía sus relaciones con el poder imperial. Así, la "doctrina" de política exterior de Maduro -como ideas y pensamiento- ha sido "una supervivencia del régimen político chavista en condiciones adversas" (Romero y Mijares), sin el carisma y las condiciones del Comandante.

La Alianza del Pacífico resultaría a la postre el actor clave del aislamiento regional de Venezuela; no porque sus miembros se lo propusieran, sino porque cambiaron los gobiernos y las alianzas gubernamentales en otros países y ellos modificaron sus visiones respecto de Venezuela. Los gobiernos de Argentina (Cristina de Kirchner), Brasil (Rousseff) y Uruguay (Mujica), que habían sido críticos del nuevo modelo de regionalismo liberal, ahora, con Macri, Temer y Vázquez, le eran receptivos.

\section{Referencias bibliográficas}

Aranda, Gilberto, El proyecto Chávez (1990-2007), Santiago, Editorial Universitaria, 2013. Aranda, Gilberto y Sergio Salinas, Bolívar según Chávez. Ensayo de una tendencia, Santiago, RIL Editores, 2013.

Aranda, Gilberto y Salinas, Sergio, "La expansión del ideal bolivariano como mito de cambio político", en Jorge Riquelme, Máximo Quitral y Carlos Rojas (comps.), América Latina: Nuevas miradas desde el Sur, Santiago, Minimocomún Ediciones, 2013a.

Bernal-Meza, Raúl, "Latin American Concepts and Theories and Their Impacts to Foreign Policies", en José F. S. Saraiva (ed.), Concepts, Histories and Theories of International Relations for the $21^{\text {st }}$ Century, Brasília, Instituto Brasileiro de Relações Internacionais, Universidad de Brasília, 2009.

Bernal-Meza, Raúl, "El pensamiento internacionalista en la era Lula", Estudios Internacionales 43 (167), 143-172, 2010.

Bernal-Meza, Raúl. "El escenario sudamericano frente a la globalización: regionalismos, Estado y política exterior”, en Raúl Bernal-Meza y Silvia Álvarez (Eds.), Asuntos de América Latina, Santiago, Universidad de Santiago de Chile, 2012.

Bernal-Meza, Raúl and Steen F. Christensen, Steen F., "Latin America's Political and Economic Responses to the Process of Globalization", en Manuela Nilsson and Jan 
Gustafsson (eds.), Latin American Responses to Globalization in the $21^{\text {st }}$ Century, Basingstoke, Palgrave Macmillan, 2012.

Bernal-Meza, Raúl, América Latina en el Mundo. El pensamiento latinoamericano y la teoría de relaciones internacionales, Buenos Aires, Nuevohacer/Grupo Editor Latinoamericano, [2005], 2013.

Briceño Ruiz, José, "Los cambios en la política exterior de Venezuela y 'el giro hacia el sur' de Chávez”, en Lincoln Bizzozero e Isabel Clemente (coords.), La política internacional en un mundo en mutación, Montevideo, Ediciones de la Banda Oriental y Universidad de la República, 2011.

Corrales, Javier, Changes in Regime Type and Venezuela's New Foreign Policy, Florida, International University, 2009.

Domínguez, Jorge I., La política exterior de Cuba (1962-2009), Madrid, Editorial Colibrí, 2009.

Duarte Villa, Rafael, "Brasil-Venezuela: cooperação e dificultades nas relações bilaterais contemporáneas", en Antônio Carlos Lessa e Henrique Altemani de Oliveira (org.), Parcerias Estratégicas do Brasil: os significados e as experiências tradicionais, Belo Horizonte, Fino Traço Editora, Volume I, 2013.

Fermandois, Joaquín, "De país problemático a nación preferida”, en Mario Artaza y César Ross (eds.), La política exterior de Chile, 1990-2009, Santiago, RIL Editores y USACH, Volumen 1, 2012.

Flemes, Daniel, "La política exterior colombiana desde la perspectiva del realismo clásico", en Stefan Jost (ed.), Colombia: ¿una potencia en desarrollo? Escenarios y desafíos para su política exterior, Bogotá, Konrad Adenauer Stiftung, Segunda Edición, 2013.

Giacalone, Rita, "Cambios en el Regionalismo de Venezuela y Colombia (1990-2013): del Grupo de los Tres al ALBA y la Alianza del Pacífico", en Noemí Mellado (dir. y ed.), Regionalismo Latinoamericano: dimensiones actuales, Córdoba, Lerner Editora S.R.L, 2014.

González Urrutia, Edmundo. "Las dos etapas de la política exterior de Chávez", Nueva Sociedad 205, 2006.

González Urrutia, Edmundo, La política exterior de Venezuela y la Nueva Geopolítica Internacional, Caracas, Instituto Latinoamericano de Investigaciones Sociales ILDIS y Centro de Estudios Estratégicos y Relaciones Internacionales, 2008.

Gullo, Marcelo, La insubordinación fundante. Breve historia de la construcción del poder de las naciones, Buenos Aires, Biblos, segunda edición, [2008], 2010.

López, Rodolfo, "Nuevo instrumento de regionalismo. Resultados de la Iniciativa para la Integración de la Infraestructura Regional Sudamericana (IIRSA)", en Raúl Bernal-Meza y Silvia Quintanar (eds.), Regionalismo y Orden Mundial: Suramérica, Europa, China, Buenos Aires, Nuevohacer/Grupo Editor Latinoamericano y Universidad Nacional del Centro de la Provincia de Buenos Aires, 2012.

López-Portillo, Felicitas, "La Venezuela de Hugo Chávez (1935-2000)", en Adalberto Santana (coord.), Venezuela: política y migración, México D.F., Centro de Investigaciones sobre América Latina y el Caribe, Universidad Nacional Autónoma de México, 2008.

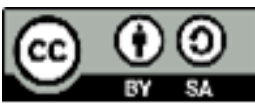


Malamud, Andrés y Gardini, Gian, "Has Regionalism Peaked? The Latin American Quagmire and Its Lessons", International Spectator 47(1), 16-33, 2014.

Márquez R., Martha, "Los retos de Venezuela ante la Alianza del Pacífico", en Eduardo Pastrana B. y Hubert Gehring (eds.), Alianza del Pacífico: mitos y realidades, Cali, Editorial Universidad Santiago de Cali, 2014.

Morales P., Salvador, "Política exterior de Venezuela en los comienzos del siglo XXI", en Adalberto Santana (coord.), op.cit., 2008.

Narvaja de Arnaoux, Elvira, El discurso latinoamericanista de Hugo Chávez, Buenos Aires, Biblos, 2008.

Pérez, Jesús Arnaldo. "Los venezolanos y su democracia". Revista DEP, Diplomacia, Estrategia, Política, 1, 208-228, 2004.

Quintanar, Silvia, "La Alianza Bolivariana para los Pueblos de Nuestra América (ALBA). Un nuevo proceso de regionalismo latinoamericano", en Raúl Bernal-Meza y Silvia Quintanar (eds.), op. cit., 2012.

Quintanar, Silvia, "Convergencias y divergencias en las estrategias de integración y cooperación energética regionales de Venezuela y Brasil”, en Raúl Bernal-Meza y Silvia Quintanar (eds.), op. cit., 2012.

Romero Carlos A., "El pasado y presente de la política exterior de Venezuela", en Marisa Ramos Rollón (ed.), Venezuela: Rupturas y continuidades del sistema político (1999-2001), Caracas, PDVSA y Universidad de Salamanca, 2001.

Romero, Carlos A., "La politique exterieure de Chávez et l'Union Européenne”, en Daniel van Eeuwen (dir.), L'Amérique latine et l'Europe a l'heure de la mondialisation. Dimensions des relations internationales, Paris, Karthala, 2002.

Romero, Carlos A., "Venezuela y Estados Unidos: ¿una relación esquizofrénica?”, Nueva Sociedad, 206, 2005.

Romero, Carlos A., La entrada de Venezuela en el MERCOSUR: Repercusiones internas, Caracas, ILDIS, 2007.

Romero, Carlos A., "La política exterior de la Venezuela bolivariana", Working Paper n 4, julio, 2010.

Romero, Carlos A., "China and Venezuela: ideology or pragmatism", en Leila Ferreira y José Augusto Guilhon Albuquerque, (eds.), China and Brazil: challenges and opportunities, Campinas, Unicamp y Anablume Editora, 2013.

Romero, Carlos A., "Crisis política y transiciones en Venezuela", Cadernos Prolam/USP, 15 (27), 64-87, 2016.

Romero, Carlos A., y Mijares, Víctor M., From Chávez to Maduro: Continuity and Change in Venezuelan Foreign Policy, Contexto Internacional 38 (1), 191-227, 2016.

Russell, Roberto, Política exterior y toma de decisiones en América Latina. Buenos Aires, RIAL y Grupo Editor Latinoamericano, 1990.

Santana, Adalberto. "Introducción", en Adalberto Santana (coord.), Venezuela: política y migración, op. cit., 2008.

Saraiva, Miriam y Briceño, José, “Argentina, Brasil e Venezuela: as diferentes percepções sobre a construção do Mercosul”, Revista Brasileira de Política Internacional, 52(1), 149166, 2009.

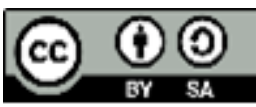


Serbin, Andrés, "La política exterior de Venezuela y sus opciones en el marco de los cambios globales y regionales", Estudios Internacionales, 26(104), 637-680, 1993.

Serbin, Andrés, Chávez, Venezuela y la reconfiguración política de América Latina y el Caribe, Buenos Aires, Siglo XXI Editores, 2010.

Serbin, Andrés, “Autonomía y normalización: ¿El fin del excepcionalismo cubano?”, en Andrés Serbin (coord..), ¿Fin de ciclo y reconfiguración regional? América Latina y las relaciones entre Cuba y los Estados Unidos, Buenos Aires, CRIES, 2016.

Serbin, Andrés y Serbin Pont, Andrei, "Quince años de de Política exterior Bolivariana: ¿entre el Soft-balancing y la Militarización?”, Pensamiento Propio, 19 (39), 2014.

Velázquez Flores, Rafael, Factores, bases y fundamentos de la política exterior de México, México D.F.: Plaza y Valdés S.A., Segunda edición, 2007.

\section{Sitios electrónicos:}

Cabieses, Manuel (2005), "Dónde va Chávez", Voltairenet org. http://www.voltairenet.org/article141731.html. Visitado el 11 de marzo de 2015.

Mijares, Victor y Romero, Carlos (2016), "Venezuela bajo observación", en Venezuela en la mira, September 29, 2016. http://temas.cult.cu/venezuela-bajo-observacion/, Visitado el 10 de octubre de 2016. 